\title{
Learning and retrieval rate of words presented auditorily and visually
}

Citation for published version (APA):

Brand, N., \& Jolles, J. (1985). Learning and retrieval rate of words presented auditorily and visually. Journal of Genetic Psychology, 112(2), 201-210. https://doi.org/10.1080/00221309.1985.9711004

Document status and date:

Published: 01/01/1985

DOI:

10.1080/00221309.1985.9711004

Document Version:

Publisher's PDF, also known as Version of record

\section{Please check the document version of this publication:}

- A submitted manuscript is the version of the article upon submission and before peer-review. There can be important differences between the submitted version and the official published version of record.

People interested in the research are advised to contact the author for the final version of the publication, or visit the DOI to the publisher's website.

- The final author version and the galley proof are versions of the publication after peer review.

- The final published version features the final layout of the paper including the volume, issue and page numbers.

Link to publication

\footnotetext{
General rights rights.

- You may freely distribute the URL identifying the publication in the public portal. please follow below link for the End User Agreement:

www.umlib.nl/taverne-license

Take down policy

If you believe that this document breaches copyright please contact us at:

repository@maastrichtuniversity.nl

providing details and we will investigate your claim.
}

Copyright and moral rights for the publications made accessible in the public portal are retained by the authors and/or other copyright owners and it is a condition of accessing publications that users recognise and abide by the legal requirements associated with these

- Users may download and print one copy of any publication from the public portal for the purpose of private study or research.

- You may not further distribute the material or use it for any profit-making activity or commercial gain

If the publication is distributed under the terms of Article $25 \mathrm{fa}$ of the Dutch Copyright Act, indicated by the "Taverne" license above, 
Myers, I. B. (1962). The Myers-Briggs Type Indicator. Palo Alto: Consulting Psy-
chologists Press. chologists Press.

males and males .riks, J. L., \& Loftus, E. F. (1979). Eyewitness accounts of feSiegel, J. M. \& Loftus, E. F. Applied Psychology, 64, 339-347.

ness testimony. Bulletin of the Psychonomic Society, and life stress upon eyewitVon Franz, M. L. (1979). The inferior function In M. C. vin Fraze

\& J. Hillman,

(Eds.). (1984). Eyewitness testimony: Psychological perWhipectives. New York: Cambridge University Press.

testimony." M. (1909). The observer as reporter: A survey of the "psychology of testimony." Psychological Bulletin, 6, 153-170.

Wolk 5 , C. (1978). The symbolic quest. Princeton: Princeton University Press. function of etle, J. (1974). Intentional performance and incidental learning as a function of personality and task dimensions. Journal of Personality and Social

Received January 2, 1985

\section{Learning and Retrieval Rate of Words Presented Auditorily and Visually}

NICO BRAND

JELLEMER JOLLES

Psychiatric University Clinic

University of Utrecht, the Netherlands

ABSTRACT. Mode of presentation (visual or auditory) of a multitrial free recall test is stressed as an important factor in improving the diagnosis of certain neurological patients. For further use in neuropsychological research, an experiment was carried out using normal subjects, in which the effects of presentation mode and order of modality were investigated. There were no differential effects of these variables on severa parameters, such as the number of words recalled and the learning curve. The time needed for the responses in immediate recall was the same in both auditory and visual conditions. In delayed recall, however, the interresponse times were significantly shorter whe words had been, prewever, the indert thpons results are discussed in light of further application in the field of neuropsychology.

MULTITRIAL FREE RECALL TESTS offer a useful paradigm for re search into verbal memory processes (Engle, Clark, \& Cathcart, 1980; Penney, 1975). These learning tests have proven their value not only in the psychological laboratory but also in clinical neuropsychological practice in the assessment of patients with cognitive deficits (Lezak, 1976; Luria, 1976 exceed short-term memory (STM) capacity (e.g, a 15-word learning test) are tools to examine the organization of verbal memory. Healthy subjects use strategies such as rehearsal and semantic clustering to facilitate the learning process (Sternberg \& Tulving, 1977). Consequently, the number of

The research presented here was supported by Grant No. 560-264-010 from the Netherlands Organization for the Advancement of Pure Research.

Requests for reprints should be sent to Nico Brand, Psychiatric University Clinic, Nicolaas Beetsstraat 24, 3511 HG Utrecht, the Netherlands. 
items that are correctly recalled increases with trials and reaches an asymp tote within five trials. Patients with frontal neocortical dysfunctions char acteristically lack organizing ability and have a flat learning curve: The number of words recalled does not increase with the number of trials (Luria, 1976). These frontal patients show many errors of repetition and sometimes a rigid, stereotyped order of recall Storage, however, does not seem to be affected beca sem (Luria, 1976; Jolles, in preparalion). Patients normal (Luria, 1976; Jolles, in preparation). Patients who suffer from lesions in the limbic system (e.g., Korsakoff's syndrome) have a simila plateau-shaped curve. Their performance is due to great instability and to reciprocal inhibition of traces rather than to inactivity or stereotyped reactions and the absent use of strategies. Patients with damage in the posterio neocortex characteristically show learning in a multitrial learning test, but they reach an asymptote sooner than do healthy subjects. According to several authors, their memory deficits are modality and materal specific (e. (e.g., specific for words presented auditorily or faces presented visually) For instance, Luria $(1976,1980)$ noted that patients with a lesion in the lef temporal lobe failed on the auditory version of his 10-word learning test and showed only a recency effect. With a visually presented version (written), the performance of these patients was better. Luria explained the findings as being due to retroactive inhibition of the earlier elements in audioverba memory. Others (Basso, Spinnler, Vallar, \& Zanobio, 1982; Warrington, Logue, \& Pratt, 1971) have reported on patients With lesions in the left Logue, \& Pratt, hemisphere who had a very short auditory digit span but nearly normal visual span, whereas expressive language functions were intact.

Studies in experimental psychological literature on the comparison between auditory and visual presentation of free recall lists have shown that auditory presentation leads to somewhat enhanced retention of the last words of the list (Engle, Clark, \& Cathcart, 1980; Engle \& Roberts, 1982; Rae, 1979; Watkins \& Watkins, 1977). Unfortunately, most word-learning tests used in clinical neuropsychology are presented auditorily because visu visual presentation necessitates the use of a sophisticated apparatus, such as slide projectors and/or computers. Consequently, there is a lack of reliable methods to compare the learning capacity for words presented by either sensory modality.

The present study dealt with the comparison of auditory and visual modes of presentation of a word-learning test by way of tape recorder and microcomputer. The aim was to establish the efficacy of the procedure for later use in clinical neuropsychological practice (differentiation between palater use in clicicion patients with modality-specific memory deficits). Therefore, both modes of presentation were compared with respect to several parameters, such as the immediate and delayed recall, delayed recognition, learning curve, errors, and the rate of retrieval processes.

\section{Method}

Subjects

The subjects participating in the experiment were 12 graduate medical students (mean age $=25.7$ years, $S D=3.8$ years) who were paid for their services. The subjects were randomly assigned to the experimental groups.

Materials

The word-learning tests used were based on the Groningen 15-word learning test (Deelman, Brouwer, van Zomeren, \& Saan, 1980). Seven versions of this test have been developed and shown to be parallel (Jolles, in preparation). Versions 3 and 4 were used in the present study. The learning list consists of 15 meaningful monosyllabic words. These words have a frequency (Linschoten, 1963) and refer to concrete objects, such as dog, moon, and bread. Also administered were recognition tests consisting of the 15 words from the corresponding learning list and 15 new but similar words drawn from the same population. The auditory presentation was done by tape recorder. The visual presentation was on a 33-cm monitor guided by a BASIS-108 microcomputer (Apple-compatible). The duration of each stimulus was $1 \mathrm{~s}$ for either presentation mode. Similarly, the interstimulus interval was 1 s. The words were composed of ASCII type capital letters, $0.6 \mathrm{~cm}$ in height. They were presented in white against a black background and in the center of the screen.

Design

To study the difference between auditory and visual modes of presentation in immediate and delayed recall and recognition, we used a $2 \times 2 \times 2$ between-subjects design. The dimensions were order of modality (visualtween-subjects design. The dimensions were order of modality (visual-
auditory, auditory-visual), order of version (3-4, 4-3), and session (first, auditory, auditory-visual), order of version $(3-4,4-3)$, and session (first,
second), with repeated measures over the last factor. The other parameters were studied in a within-subjects design.

Procedure

Each subject was tested individually. On arrival for the experiment, the subject was told that he or she would participate in a study of memory processes. Each subject sat at a table across from the experimenter during the auditory word-learning task. During the visual word-learning task, the subject confronted a television monitor at a distance of $.8 \mathrm{~m}$. For half of the 
subjects, the order of tasks and events was the following: auditory wordlearning task (aud) consisting of five trials, 20 min of distracting tests consisting of the discrimination of complex visual forms, delayed recall (aud), delayed recognition (aud), a short break, visual word-learning task (vis) consisting of five trials, $20 \mathrm{~min}$ of distraction (as above), delayed (vecall (vis), and delayed recognition (vis). The other half of the subjected recall the tests in the order vis, aud.

The test instructions were read aloud by the experimenter. The subject was required to carefully listen to (and watch, respectively) the 15 words that were presented on the tape recorder (response monitor) and to mention as many words as possible as soon as the presentation stopped. There was no restriction on the output order. The first trial was followed by four more trials in which the words were presented in identical order. The subjere were instructed, in case of doubt, not to ask the experimer. The subjects reported a word previously, although no perinent if they had reported a word previously, although no pertinent instruction was given whether it was allowed to repeat words already reported.

The verbal responses were recorded on a second tape recorder to allow the detemination in the interval between the words recalled, or the interresponse time (IRT). This analysis was performed by the microcomputer.

When the immediate recall following the fifth trial was completed, subject had to engage in the distracting tasks. After 20 min the inted, the was given to actively recall the words learned (delayed recall). Thistion followed immediately by a dhe words learned (delayed recall). This wa followed immediately by a delayed recognition test, involving yes/no recognition of the 15 words intermixed in 15 different distracting words. The items in the visual recognition task were presented on the screen in a selfpaced fashion with a one-second response-stimulus interval; in the auditory condition they were read aloud by the experimenter. The binary choice was given by a vocal response in the auditory condition and by way of puh buttons in the visual test ("yes" response by the preferred hand ond " butthe other hand). The reaction times were registered for the vand and "no" by The dat anere visual mode only. (Winer 1971) statistically tested by using analysis of variance-ANOVA (Winer, 1971)-or by nonparametric methods-Wilcoxon test, Walsh test, Friedman's ANOVA (Siegel, 1968).

\section{Results}

A two-way ANOVA was carried out to assess the significance of the difference between auditory and visual modes of presentation with respect to the total score (the sum of Trials 1 through 5), delayed recall, and delayed recognition. No significant differences were found for any of these three parameters: There was no effect due to modality, order of version and session; and there were no ef fect due to modality, order of version, and sesformed with ore no significant interactions. A second analysis was per- and repeated measures over modality and trials. It appeared that trials was the only significant factor, $F(4,40)=91.82, p<.001$. No interactions with modality were observed. The learning curves for auditory versus visual presmodality were obser in 1 .

It is readily apparent that the curves representing auditory and visual presentations coincide. $T$ tests on the scores for the individual trials were not significant. With respect to the learning curve, tests on the difference between pairs of means, according to the Newman-Keuls method (Winer 1971), revealed a significant increase in learning between Trials 1 and 2, 2 and 3 , and 3 and 5 . In view of the possibility that a subtle difference in performance on both modes of presentation might reflect itself in the rate at which the words are recalled, an analysis was performed on the intervals bewhich the words are recalled, an aly interresponse time (IRT). The medium tween the verbal responses, or the interresponse time (IRT). The medium IRT was calculated per subject and per trial. Figure 2 shows the median data for the groups of subjects.

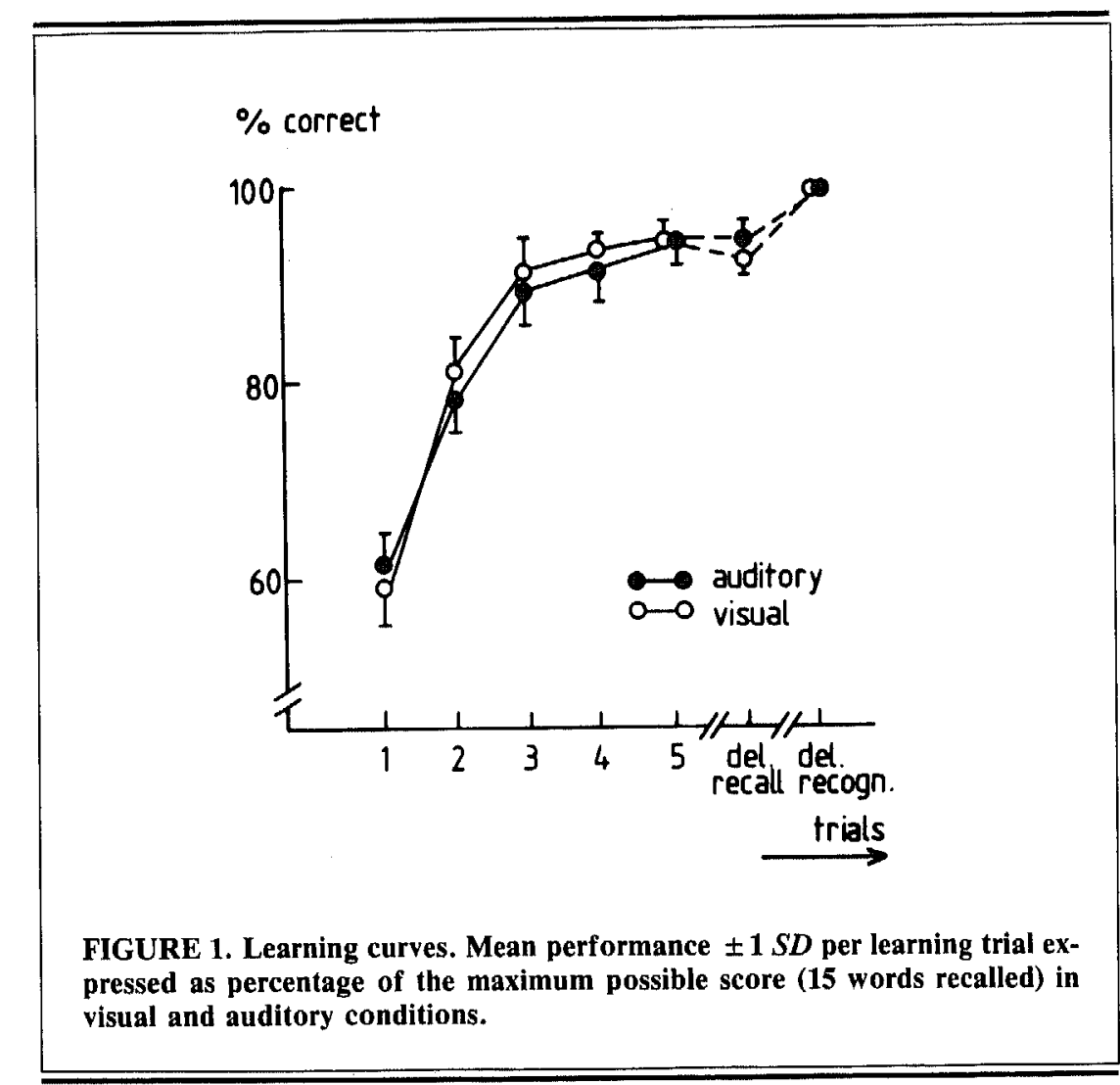




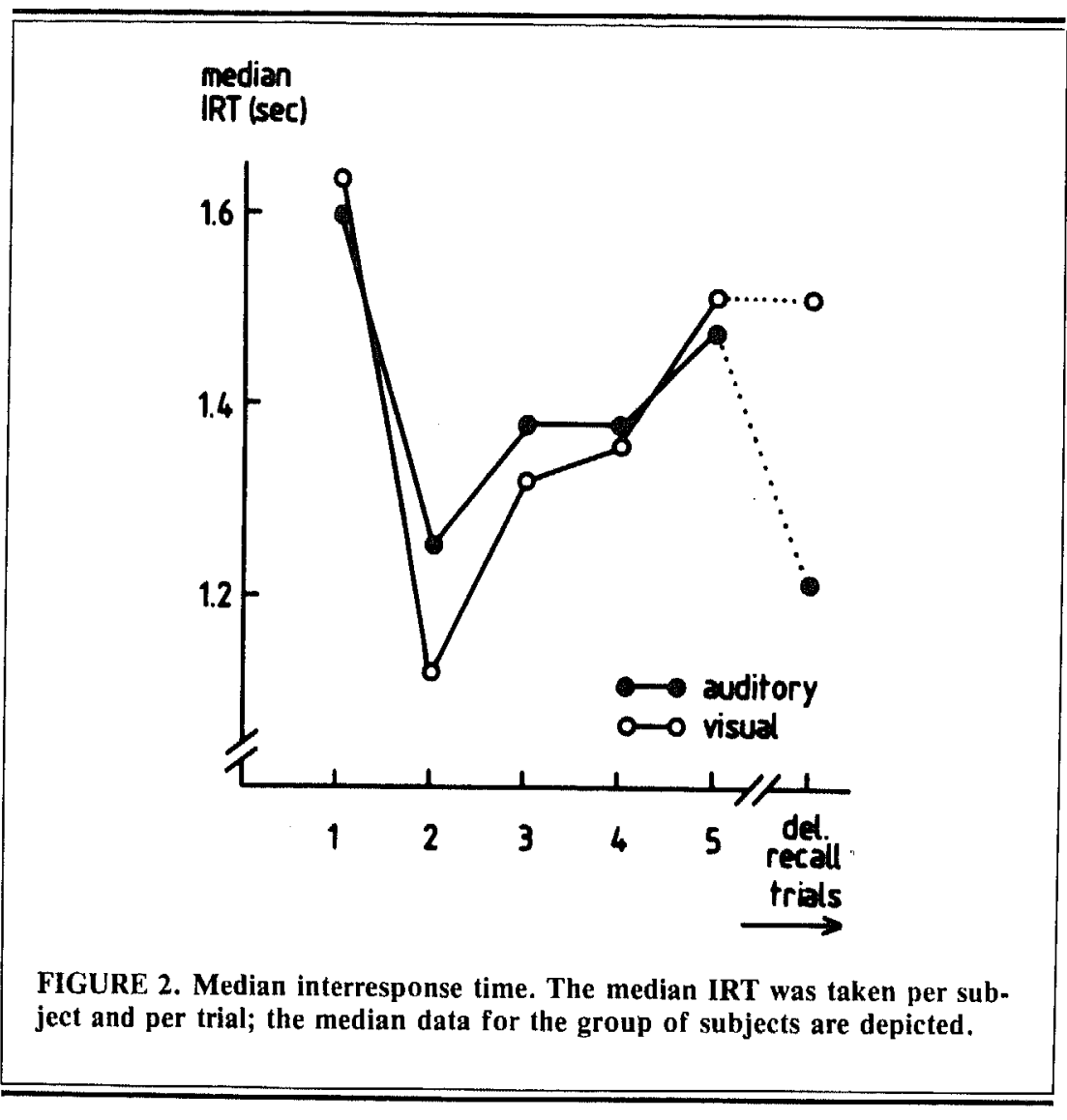

It appeared that the IRT significantly decreased between Trials 1 and 2 and increased between Trials 2 through 5 (Friedman's ANOVA). For the five trials in the learning phase, no differences were observed between the IRTs corresponding to auditory and visual presentations; a statistically significant difference was noted, however, in the delayed recall (Walsh sest $p<011$ ). The median IRT in the auditory condition was $20 \%$ lows test, in the visual condition. A post hoc analysis was carried out on the raw IRTs to assess the nature of the differential response. Figure 3 shows a frequency distribution of the IRTs in both modes of presentation. It appeared that the visual distribution was shifted toward shorter IRTs by $.5 \mathrm{~s}$.

The reaction times measured in the delayed recognition test could not be compared between the two modality conditions because of differences in the paradigm used. It was, however, observed that in the visual condion the RTs for the positive ("yes") responses were significantly shorter than

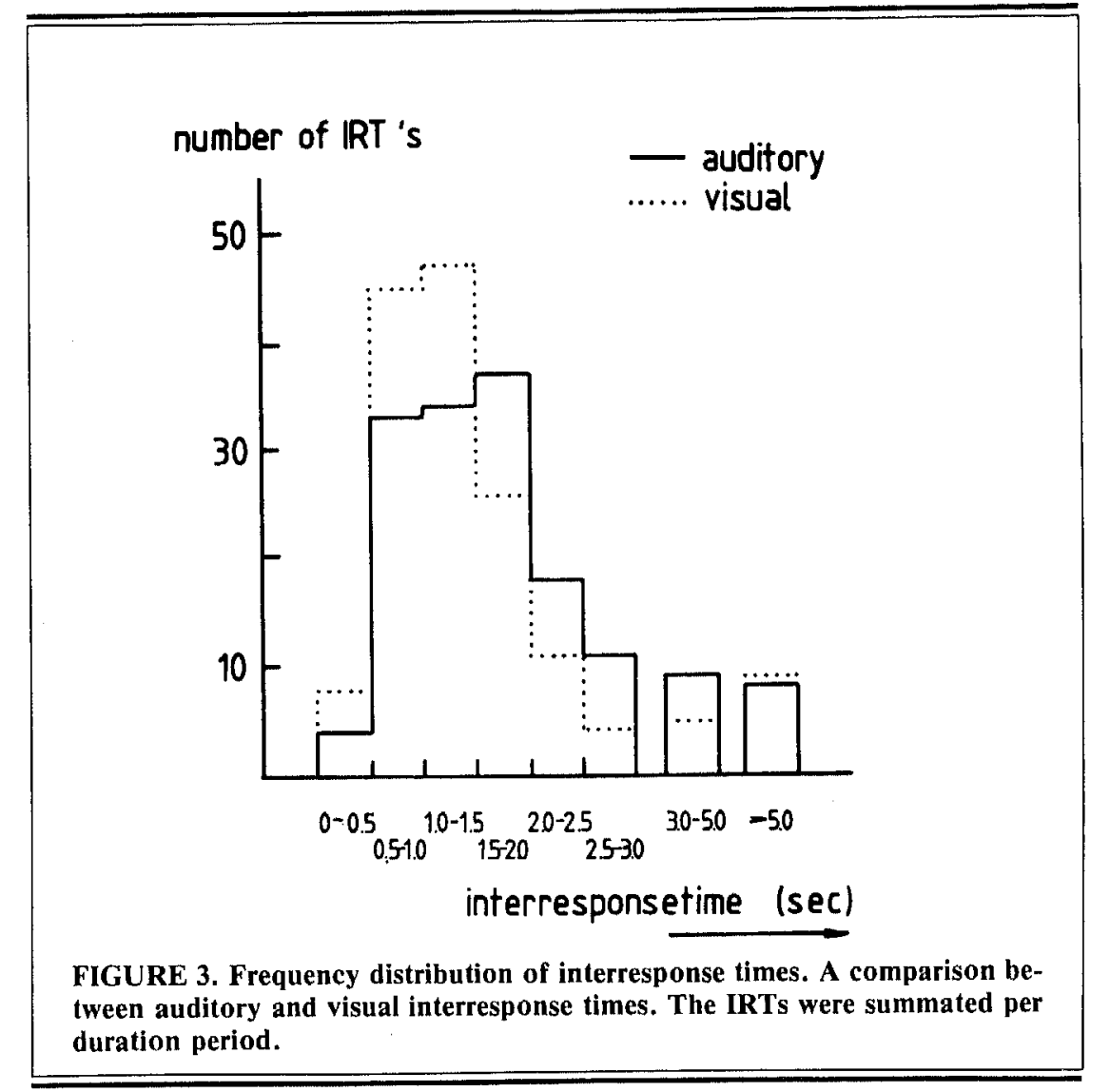

those for the negative responses (Wilcoxon test, $p<.05$ ). This may have been due to the use of the nonpreferred hand for the "no" responses.

With respect to the number of errors of commission made in the learning trials, no statistically significant effects were found between both modes of presention. Significantly more errors of repetition were made, however, in the visual condition (Wilcoxon test, $p<.05$ ): The median number of repetitions across subjects was 4.0 , compared to 1.5 in the auditory condition.

\section{Discussion}

The main findings reported in the present study support the notion that the number of words recalled in healthy subjects is the same when the words are presented auditorily or visually. The two conditions were not different with 
respect to the learning curves over the five learning trials. The total scores and the delayed recall and delayed recognition scores were also the same. In addition, the serial position curve for the first trial was very similar for the auditory and visual presentations. (A clear-cut primasy volving the first three words in the lists and a dip at the fou wo found in results are not shown.)

The auditory and visual learning curves manifested an of learning (Figure 1); the subjects reated an equivalent rate of learning (Figure 1); the subjects reached a plateau at the third to fourth trial. Consequently, the learning curves thus found can be used as a comparison for the learning curves obtained from patients suffering from different kinds of memory deficit. This applies especially to patients suffering from frontal neocortex dysfunction, who are characterized by a flat lean ing curve (Luria, 1976).

The finding that the interresponse times measured in the learning phas were similar in the auditory and visual conditions (Figure 2) adds support to the conclusion reached above, that both conditions are equivalent with respect to the learning phase. The increase in median IRT measured from Trial 2 through 5 may reflect the increase in the number of words recalled. The significantly higher IRT in Trial 1 may have to do with the novelty of the words presented; it suggests that more time is needed to retrievelty of learned words. Further research should be directed at substantiating newly teresting result. A similarly unexpected finding is the significang this inIRTs needed for delayed recall of auditorily leng is the significantly lower visually learned words. The visually learned words. The median IRT for the delayed recall in the visual condition was on the level of the fifth learning trial, but that for the This This may indicate, in the first place, that the retrieval process in trial. recall is different from that in immediate recall. It is a common obserayed that many subjects start their immediate recall by mentioning observation in the list, whereas the order in which the words are recalled in the words recall more or less follows the we delayed ecand recon place, the observed difference between auditory and visual delayed recall may indicate that the retrieval process after a delay of $20 \mathrm{~min}$ is easier after auditory presentation. Neuropsychologically, speaking a word that is seen requires a different cerebral route than speaking a word that is heard (Luria, 1980; Marcel \& Patterson, 1978). The present data suppon heard tion that the former route is less direct, which is evident in the longe notrieval time needed to recall these words. This hypothesis is the longer reinvestigated in a follow un experim

Another indication for a qualitatively and quantitatively different trieval process in both conditions is the significantly greater numberent rerors of repetition in the visual condition (nearly three times as many errors). This may indicate that the words already mentioned are not very effectively discarded from the output buffer in which the words are circulating before being spoken aloud. This adds support to the notion that there is a difference in the neuropsychological organization of auditory versus visual word-learning processes.

In conclusion, the results obtained in this study show that, in healthy subjects, auditory and visual presentation of a word-learning test gave equivalent results with respect to the number of words recalled in immediate and delayed recall and recognition. More subte differences did exist be tween both conditions in that the performance with respect to rate of delayed recall and the number of ente delayed recall and the number of errors of repetition was superior in the auditory condition. These results indicate that the test paradigm investigated in the present study can be applied to the assessment of patients suspected of modality-specific memory defects as described in the neuropsychological literature (Basso, Spinnler, Vallar, \& Zanobio, 1982; Luria, 1976; Warrington, Logue, \& Pratt, 1971). Technically, the use of a microcomputer appears to offer great advantages with respect to controlled stimulus presentation and reaction time measurement and, thus, promises to be of value for use in the clinic. Both modes of presentation are presently being
valus value for use in the clinic. Both modes of presentation are presently being
tested with neuropsychiatric patients. Preliminary results indicate that tested with neuropsychiatric patients. Preliminary results indicate that schizophrenic patients manifested a quite considerable discrepancy between
total recall and delayed recall for auditory and visual presentations. The other patients thus far investigated had a close correlation between both modes of presentation (Jolles \& Brand, unpublished observations).

\section{REFERENCES}

Basso, A., Spinnler, H., Vallar, G., \& Zanobio, M. E. (1982). Left hemisphere damage and selective impairment of auditory verbal short term memory: A case study. Neuropsychologia, 20(3), 263-274.

Deelman, B. G., Brouwer, W. H., van Zomeren, A. H., and Saan, R. J. (1980). Functiestoornissen na trauma capitis. In A. Jennekens-Schinkel et al. (Eds.), Neurs

gult of different, D. D., \& Cathcart, J. S. (1980). The modality effect: Is it a result of different strategies? Journal of Verbal Learning and Verbal Behavior, 19

Engle, R. W., \& Roberts, J. S. (1982). How long does the modality effect persist?
Bulletin of the Psychonomic Society,

Press. D. (1976). Neuropsychological assessment. New York: Oxford University

Linschoten, J. (1963). De la Court frequentie tellingen van Nederlandse woorden (Report No. 6301). Rijks Universiteit Utrecht, Psychologisch Laboratorium.

Luria, A. R. (1980). Higher cortical functions in man. New York: John Wiley.

Marcel, A. J., \& Patterson, K. E. (1978). Word recognition and production: Reciprocity in clinical and normal studies. In J. Requinn (Ed.), Attention and performance VII. New York: Wiley \& Son. 
Penney, C. G. (1975). Modality effects in short term verbal memory. Psychological Bulletin, 82, 68-84.

Rae, G. (1979). Effect on word meaningfulness on primary and secondary memory. Journal of General Psychology, 101, 175-181.

Rey, A. (1964). L'examen clinique en psychologie. Paris: Presses Universitaires de France.

Siegel, S. (1968). Nonparametric statistics for the behavioral sciences. New York:

Sternberg, R. J., \& Tulving, E. (1977). The measurement of subjective organization in fring

in 9, 377-387. Watkins, $O$.

fects of word frewatkins, M. J. (1977). Serial recall and the modality effect: Ef-

Winer, B. J. (1971). Statistical principles in experimental design. New York: McGraw-Hill.

Received January 2, 1985
The Influence of

Embellishment and Prequestions

on Free Recall of a Text

GERRIT VAN DAM

MICHÈLE BRINKERINK-CARLIER INEKE KOK

Psychological Laboratory

University of Utrecht, Holland

ABSTRACT. The influence on free recall of the addition of embellishing details to the constituent scenes of a text was studied as a function of the salience of the embellished scenes within the overall content. The relative sallence of the scenes that questions. In Experiment $1(n=52)$, the effectiveness of the prequestions was tested, in Experiment $2(n=48)$, the presentation of prequestions was combined orthogonally with embellishment of the scenes. The results indicate that the effects of prequestions and embellishment appear to be additive. Embellishment of half of the scenes appears to be most effective when the salience of the relevant scenes has been enhanced by presentation of appropriate prequestions.

WHEN SUBJECTS RECALL a previously studied text, they are apt to omit a considerable portion of the originally learned material, which nonetheless may appear accessible under suitable conditions. For instance relatively high recognition scores may be found in cases in which free recall fails. Anderson and Pichert (1978) have shown that a change of perspective in the subject prior to recall may result in enhanced retrieval of information af is congruent with the new point of view. Also, occasional intertur of the process of free recall to urge the subjects to reproduce the text more completely appears to be a method of producing an increase in the amount of recalled information (Van Dam \& Brinkerink-Carlier, 1983a).

Generally, knowledge about the influence of retrieval cues on prose recall is limited (Johnson, 1982). In this respect, it is interesting to note a

Requests for reprints should be sent to Gerrit van Dam, Psychological Laboratory University of Utrecht, Varkenmarkt 2, 3511 BZ Utrecht, Holland.

211 